Stotz M, Gerger A, Eisner F, Szkandera J, Loibner H, L Ress A, Kornprat P, A Zoughbi W, Seggewies FS, Lackner C, Stojakovic T, Samonigg H, Hoefler G, Pichler M (2013) Increased neutrophillymphocyte ratio is a poor prognostic factor in patients with primary operable and inoperable pancreatic cancer. Br J Cancer 109: $416-421$.

Szkandera J, Absenger G, Liegl-Atzwanger B, Pichler M, Stotz M, Samonigg H, Glehr M, Zacherl M, Stojakovic T, Gerger A, Leithner A (2013) Elevated preoperative neutrophil/lymphocyte ratio is associated with poor prognosis in soft-tissue sarcoma patients. Br J Cancer 108: 1677-1683.

(c) (1) (2) This work is licensed under the Creative Commons Attribution-NonCommercial-Share Alike 3.0 Unported License. To view a copy of this license, visit http://creativecommons. org/licenses/by-nc-sa/3.0/

\title{
Reply: Comment on 'A derived neutrophil to lymphocyte ratio predicts clinical outcome in stage II and III colon cancer patients'
}

\author{
J Szkandera ${ }^{1}$, M Pichler ${ }^{1}$, M Stotz ${ }^{1}$ and A Gerger ${ }^{\star}, 1$ \\ ${ }^{1}$ Division of Clinical Oncology, Department of Medicine, Medical University of Graz, Auenbruggerplatz 15, 8036 Graz, Austria
}

We would like to thank Balta et al (2013) for their valuable comments and suggestions on our study 'A derived neutrophil to lymphocyte ratio predicts clinical outcome in stage II and III colon cancer patients'. The results of our study show that the derived neutrophil to lymphocyte ratio (dNLR; absolute count of neutrophils divided by the absolute white cell count minus the absolute count of neutrophils) and the neutrophil to lymphocyte ratio (NLR) are independent prognostic markers for time to recurrence and overall survival in patients with stage II and III colon cancer (Absenger et al, 2013). In contrast to many other previously proposed biomarkers, the dNLR and NLR are relatively cheap and easily determinable laboratory parameters, which would allow a widespread clinical use.

Recent data indicate that inflammation plays a critical role in the pathogenesis and progression of cancer. Systemic inflammatory response to tumours causes changes in the haematological components. The dNLR and NLR have recently been shown to negatively influence the clinical outcome in various cancer entities, including kidney cancer, soft-tissue sarcoma, pancreatic cancer and colon cancer (Procter et al, 2012; Absenger et al, 2013; Stotz et al, 2013; Szkandera et al, 2013; Pichler et al, 2013a). In most studies including our study, however, major potential confounding factors, such as local or systemic infection, ischaemia, acute coronary syndrome, metabolic syndrome, diabetes mellitus and renal or hepatic dysfunction, that might affect the neutrophil and lymphocyte counts have not been taken into account (Tamhane et al, 2008; Azab et al, 2012; Buyukkaya et al, 2012; Biyik et al, 2013; Gary et al, 2013). As the preoperative white blood cell count was obtained within 3 days before surgery in our study, at least local or systemic infections or inflammatory diseases could be relatively reliable excluded. However, we absolutely agree with Balta et al (2013) that a combination of multiple serum inflammatory biomarkers such as dNLR, NLR, CRP, fibrinogen, platelet to lymphocyte ratio and all possible confounding factors should be included in further studies, preferentially in prospective trials (Shiu et al, 2008; Demirkol et al, 2013; Son et al, 2013; Pichler et al, 2013b).

\section{CONFLICT OF INTEREST}

The authors declare no conflict of interest.

\section{REFERENCES}

Absenger G, Szkandera J, Pichler M, Stotz M, Arminger F, Weissmueller M, Schaberl-Moser R, Samonigg H, Stojakovic T, Gerger A (2013) A derived neutrophil to lymphocyte ratio predicts clinical outcome in stage II and III colon cancer patients. Br J Cancer 109: 395-400.

Azab B, Daoud J, Naeem FB, Nasr R, Ross J, Ghimire P, Siddiqui A, Azzi N, Rihana N, Abdallah M, Azzi N, Patel P, Kleiner M, El-Sayegh S (2012) Neutrophil-to-lymphocyte ratio as a predictor of worsening renal function in diabetic patients (3-year follow-up study). Ren Fail 34: 571-576. 
Balta S, Demirkol S, Unlu M, Arslan Z, Celik T (2013) Comment on 'A derived neutrophil to lymphocyte ratio predicts clinical outcome in stage II and III colon cancer patients'. Br J Cancer; 109(12): 3125-3126.

Biyik M, Ucar R, Solak Y, Gungor G, Polat I, Gaipov A, Cakir OO, Ataseven H, Demir A, Turk S, Polat H (2013) Blood neutrophil-to-lymphocyte ratio independently predicts survival in patients with liver cirrhosis. Eur $J$ Gastroenterol Hepatol 25: 435-441.

Buyukkaya E, Karakas MF, Karakas E, Akçay AB, Kurt M, Tanboga IH, Sen N (2012) Correlation of neutrophil to lymphocyte ratio with the presence and severity of metabolic syndrome. Clin Appl Thromb Hemost doi:10.1177/1076029612459675.

Demirkol S, Balta S, Celik T, Arslan Z, Unlu M, Cakar M, Kucuk U, Demirbas S, Iyisoy A, Yokusoglu M (2013) Assessment of the relationship between red cell distribution width and cardiac syndrome X. Kardiol Pol 71: 480-484.

Gary T, Pichler M, Belaj K, Hafner F, Gerger A, Froehlich H, Eller P, Pilger E, Brodmann M (2013) Neutrophil-to-lymphocyte ratio and its association with critical limb ischemia in PAOD patients. PLoS One 8: e56745.

Pichler M, Hutterer GC, Stoeckigt C, Chromecki TF, Stojakovic T, Golbeck S, Eberhard K, Gerger A, Mannweiler S, Pummer K, Zigeuner R (2013a) Validation of the pre-treatment neutrophil-lymphocyte ratio as a prognostic factor in a large European cohort of renal cell carcinoma patients. Br J Cancer 108: 901-907.

Pichler M, Hutterer GC, Stojakovic T, Mannweiler S, Pummer K, Zigeuner R (2013b) High plasma fibrinogen level represents an independent negative prognostic factor regarding cancer-specific, metastasis-free, as well as overall survival in a European cohort of non-metastatic renal cell carcinoma patients. Br J Cancer 109: 1123-1129.
Proctor MJ, McMillan DC, Morrison DS, Fletcher CD, Horgan PG, Clarke SJ (2012) A derived neutrophil to lymphocyte ratio predicts survival in patients with cancer. Br J Cancer 107: 695-699.

Shiu YC, Lin JK, Huang CJ, Jiang JK, Wang LW, Huang HC, Yang SH (2008) Is C-reactive protein a prognostic factor of colorectal cancer? Dis Colon Rectum 51: 443-449.

Son HJ, Park JW, Chang HJ, Kim DY, Kim BC, Kim SY, Park SC, Choi HS, Oh JH (2013) Preoperative Plasma Hyperfibrinogenemia is Predictive of Poor Prognosis in Patients with Nonmetastatic Colon Cancer. Ann Surg Oncol 20: 2908-2913.

Stotz M, Gerger A, Eisner F, Szkandera J, Loibner H, L Ress A, Kornprat P, A Zoughbi W, Seggewies FS, Lackner C, Stojakovic T, Samonigg H, Hoefler G, Pichler M (2013) Increased neutrophil-lymphocyte ratio is a poor prognostic factor in patients with primary operable and inoperable pancreatic cancer. Br J Cancer 109: 416-421.

Szkandera J, Absenger G, Liegl-Atzwanger B, Pichler M, Stotz M, Samonigg H, Glehr M, Zacherl M, Stojakovic T, Gerger A, Leithner A (2013) Elevated preoperative neutrophil/lymphocyte ratio is associated with poor prognosis in soft-tissue sarcoma patients. Br J Cancer 4: 1-7.

Tamhane UU, Aneja S, Montgomery D, Rogers EK, Eagle KA, Gurm HS (2008) Association between admission neutrophil to lymphocyte ratio and outcomes in patients with acute coronary syndrome. Am J Cardiol 102: 653-657.

(c) (1) (2) This work is licensed under the Creative Commons Attribution-NonCommercial-Share Alike 3.0 Unported License. To view a copy of this license, visit http://creativecommons. org/licenses/by-nc-sa/3.0/

\title{
B

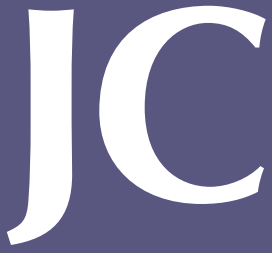

\section{Comment on 'Histopathologic evaluation of liver metastases from colorectal cancer in patients treated with FOLFOXIRI plus bevacizumab'}

\author{
F Bibeau ${ }^{\star}, 1, \mathrm{H} \mathrm{Gil}^{1}, \mathrm{~F}$ Castan ${ }^{2}$ and F Boissière-Michot ${ }^{1}$ \\ ${ }^{1}$ Pathology Department, Institut régional du Cancer Montpellier, 208 rue des Apothicaires, 34298 Montpellier Cedex 5, France and \\ ${ }^{2}$ Biostatistics Unit, Institut régional du Cancer Montpellier, 208 rue des Apothicaires, 34298 Montpellier Cedex 5, France
}

Sir,

We read with interest the article by Loupakis et al (2013) entitled 'Histopathologic evaluation of liver metastases from colorectal cancer in patients treated with FOLFOXIRI plus bevacizumab' published in the June 2013 issue of the British
Journal of Cancer. This paper clearly underlines the positive impact of FOLFOXIRI plus bevacizumab, on the extent of both tumour regression and necrosis, in resected liver metastases from colorectal cancer (CRC). The authors conclude that the addition of bevacizumab leads to a high 'histopathologic activity' as compared

*Correspondence: Dr F Bibeau; E-mail: Frederic.Bibeau@icm.unicancer.fr

Published online 24 October 2013

(C) 2013 Cancer Research UK. All rights reserved 0007-0920/13

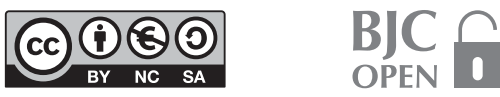

